مقارنة بعض الصفات الانثروبومترية بين لاعبي المطاولة الهو ائية و اللاهو ائبة

أ.م. عمار عبد الرحمن قبع جامعة الموصل / كلية التربية الرياضية فيد الرحية

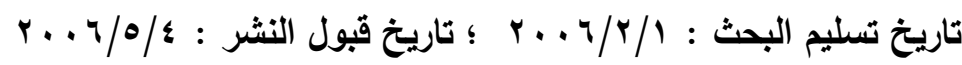

ان هناك علاقة مهمة في عملية التدريب الرياضي بين الصفات الانثرومترية وانظمـة انتاج الطاقة ، وقد هدف هذا البحث الى التعرف على بعض الصفات الانثروبومترية للاعبين

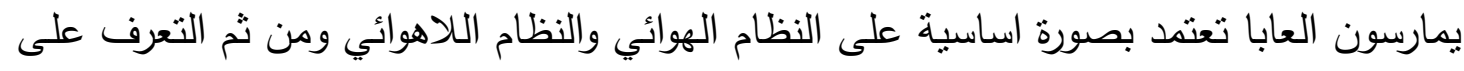
الفرق في هذه الصفات بين المجموعتنين وقد اجري البحث على عينة عمرية من لاعبي اندية

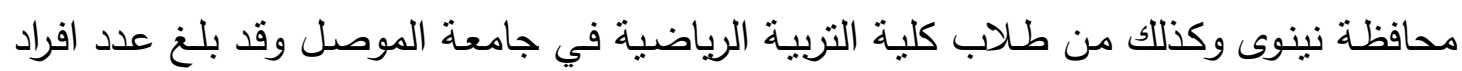

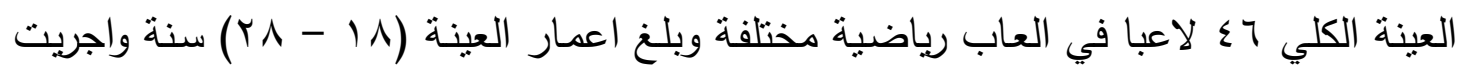

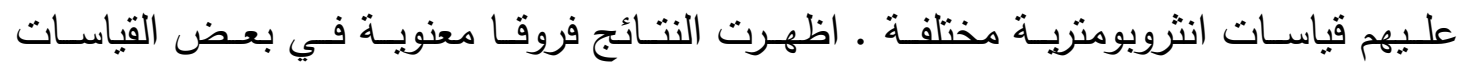

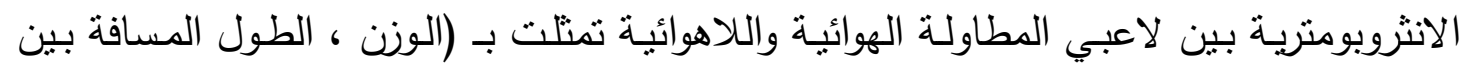

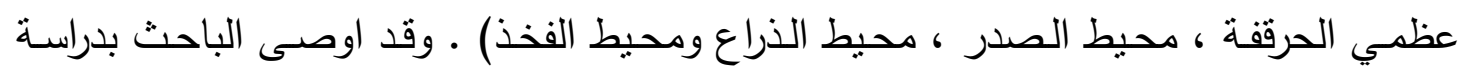
المواصفات الجسمية للاعبين عند اختيارهم لممارسة الالعاب الرياضية .

\title{
Comparison of some anthropometric properties between players of aerobic and anaerobic in durance
}

\section{Ammar Abdulrahman Quaba \\ University of Mousl - College of Sport Education}

Abstract:

There is an important relationship, in the process of training, between the anthropometric properties and the systems of energy. This research aim to know some anthropometric properties of players using aerobic and an -aerobic systems and then to the difference between these properties in the two groups. The research was carried out on players of Ninava sport clubs and college of Physical Education (Mosul University), 
The sample consisted of 46 players of different sports, their ages where (18-28) years, and their anthropometric measurements where determined . The results showed that there where differences in weight, height, iliac crest, circumference of chest, arm, and thigh). The researcher recommended to study the anthropometric properties of the players when we chose them in completion more study in this respect.

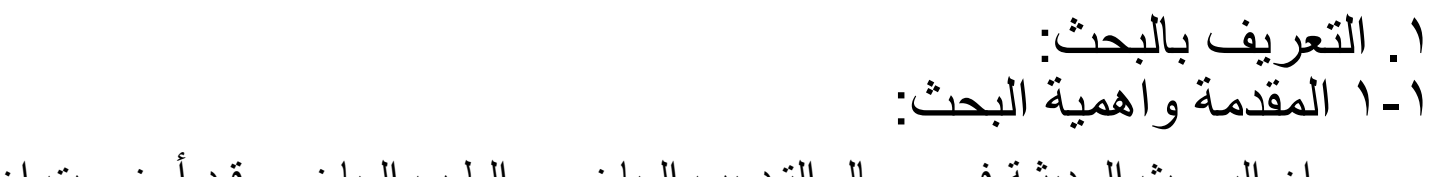

ان البحـوث الحديثة في مجـال التدريب الرياضـي والطب الرياضـي قد أوضــت ان

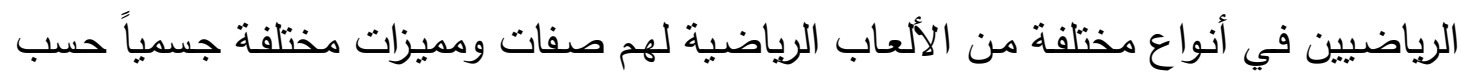

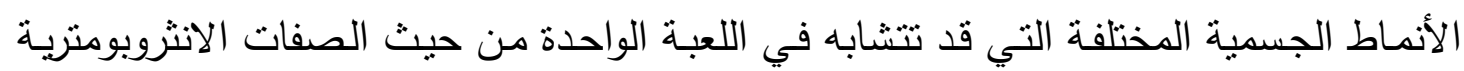

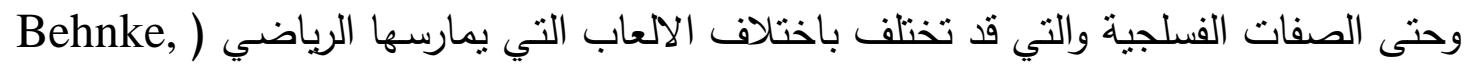

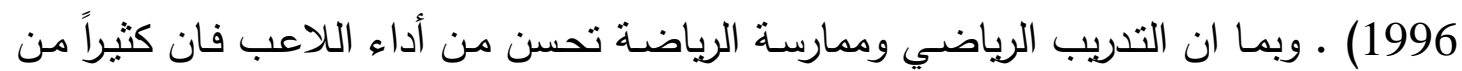

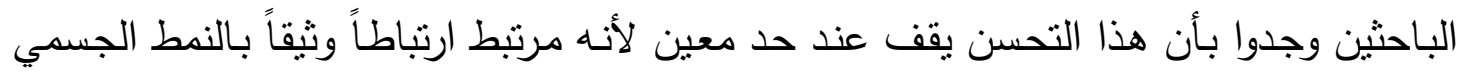

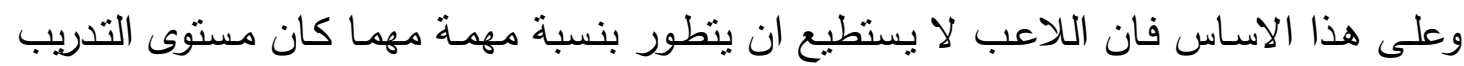

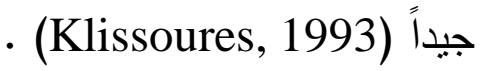

وعلى هذا الأساس فانه من المهم جداً في المجال الرياضي مستقبلاً ان يعلم الباحثون

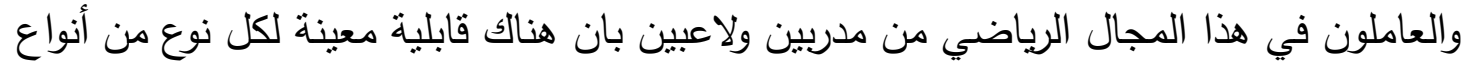

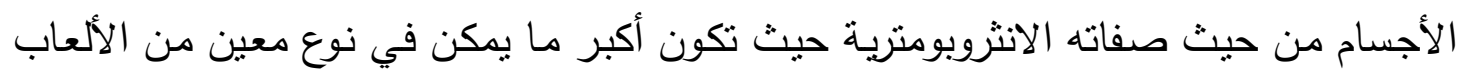

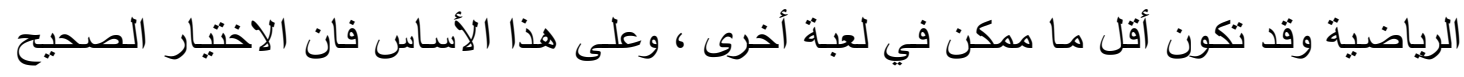

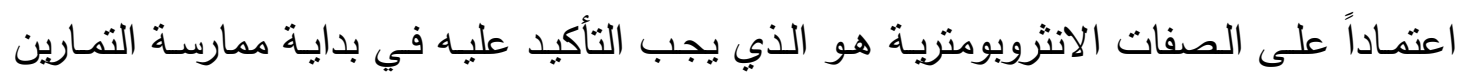
الرياضية وإلا ضاع جهد اللاعب والمدرب بدون فائدة (Cureton, 1995) •

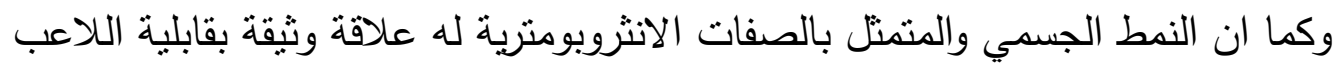

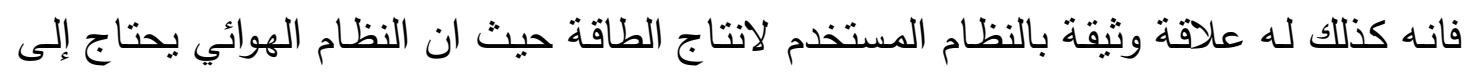
جهاز دوري تتفسي سليم وكفوء بينما يحتاج النظام اللاهوائي إلى كتلة عضلية لخزن كميات

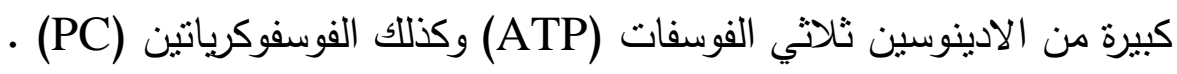

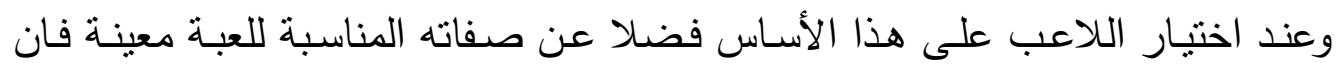
الاختيار سوف يكون دقيقاً . 
يلعب النظام الهوائي واللاهوائي دوراً مهماً في عملية النتريب الرياضي في اللعبة الواحدة ، وكذللك تلعب الأنماط الجسمية والمتمثلة في الصفات الانثروبومنرية للاعب دوراً مهماً في قابلية

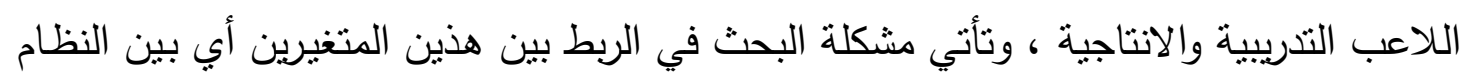

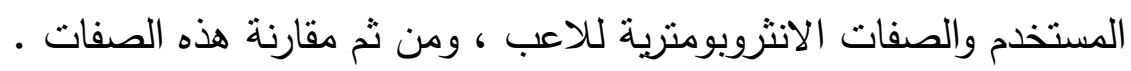

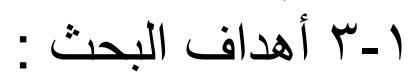

- التعرف على بعض الصفات الانثروبومترية للاعبين يمارسون العاب تعتمد بصورة أساسية

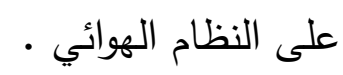

- التعرف على بعض الصفات الاثثروبومترية للاعبين يمارسون العاب تعتمد بصورة أساسية

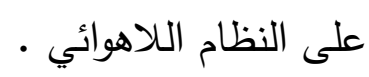
- التعرف على الفرق في بعض الصفات الانثروبومترية بين لاعبي النظام الهوائي واللاهوائي .

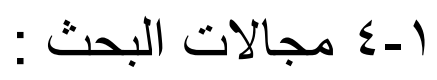
- المجال البشري : لاعبوا أندية محافظة نينوى وطلبة كلية التربية الرياضية / جامعة الموصل

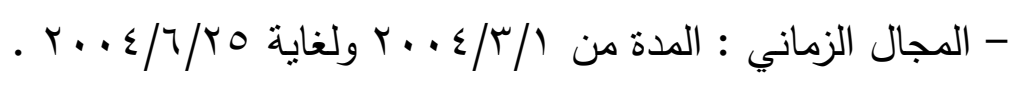

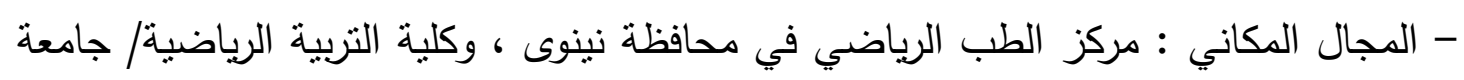

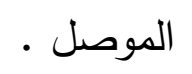

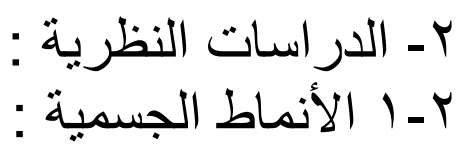

ويقصد بها هنا نوع الصفات الانثروبومترية الني تميز كل نمط من الأنماط ، حيث

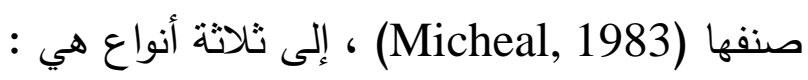
أ. النمط العضلي المتميز بكتلة عضلية واضحة ومميزة .

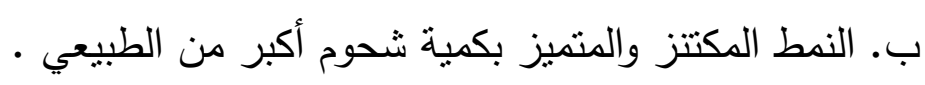

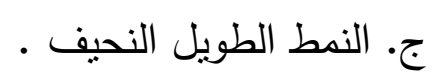

ويقول (Thomas Reilly) ان الأبطال يولدون أكثر مما هم يصنعون ، وقد أيده

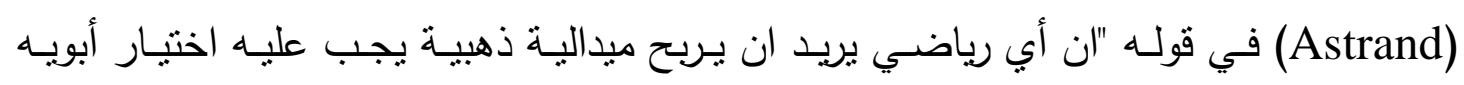
بصورة دقيقة" وقد ذهب آخرون إلى القول حتى في اختيار الأجداد (Astrand, 1979) -

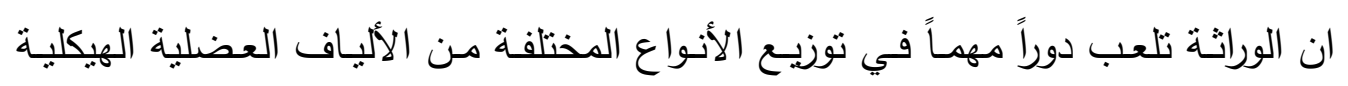
والتي تكون على نوعين : 
أ. ألياف عضلية بيضاء وتكون سريعة التقلص وغنية بالأنزيمات المحللة للكلايكوجين وتحتوي

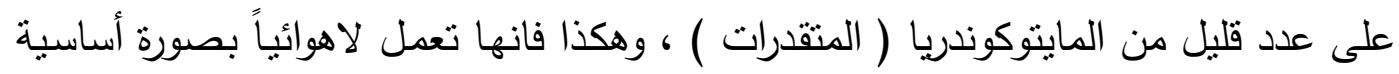

ب. ألياف عضلية حمراء وتكون بطيئة التقلص وتحتوي على كميات كبيرة من المايتوكوندريا

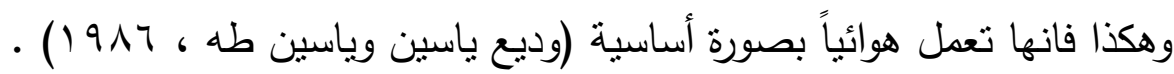

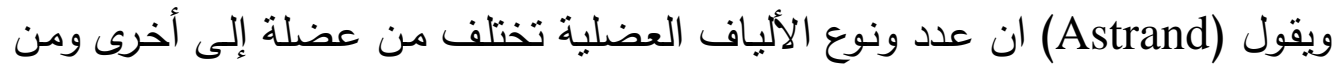

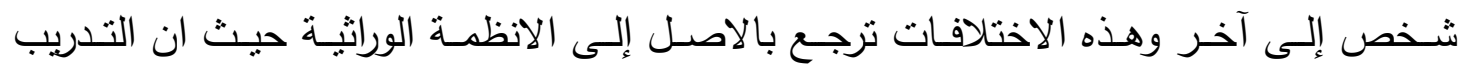

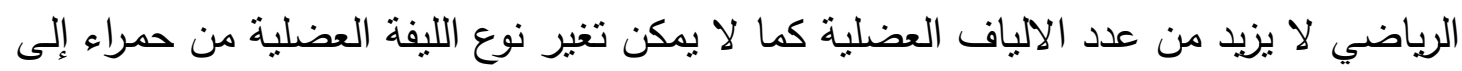

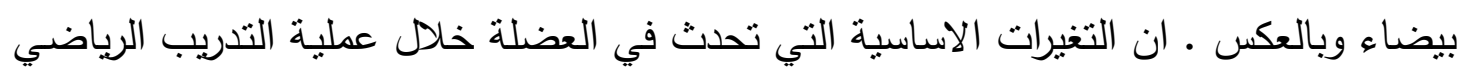

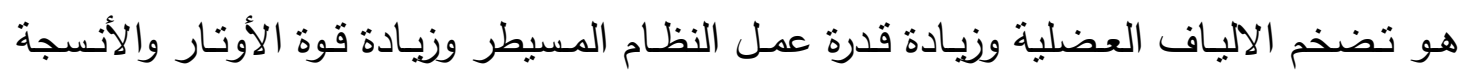
الرابطة مع زيادة في كثافة الشعيرات الدموية في الالياف العضلية (وديع ياسين وياسين طه ، ولئه

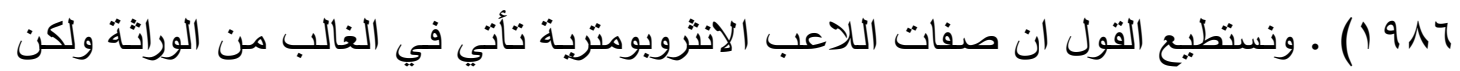
هناك بعض العوامل التي تؤثر بدرجات مختلفة نسبيا وهي التغذية والتدريب . (Astrand, 1979)

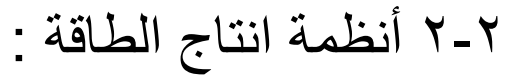
على ضوء ما ذكر سابقاً من أنواع الالياف العضلية فان كل نوع يعمل كنظام طاقة الطفة

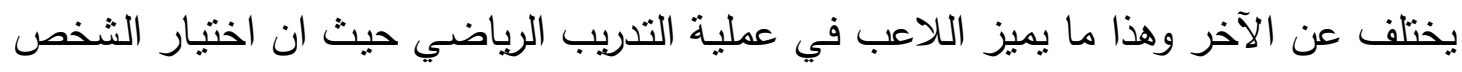

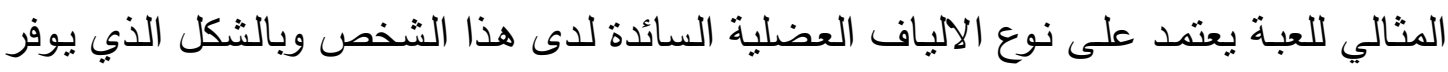

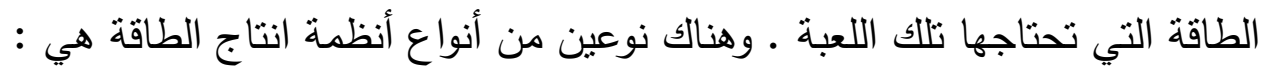

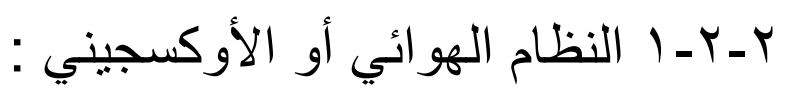

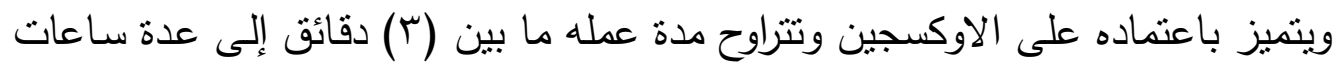

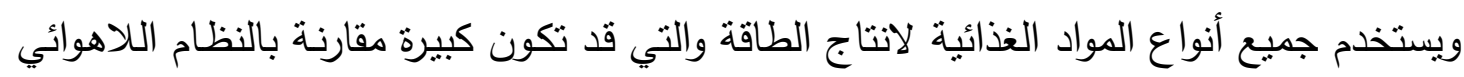

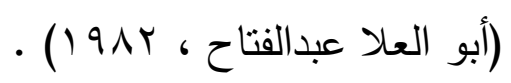




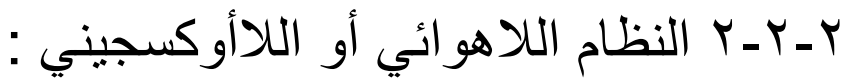

ويشمل نظام الادينوسين ثلاثي فوسفات (ATP) مـ الفوسفوكرياتين (CP) ، وكذللك

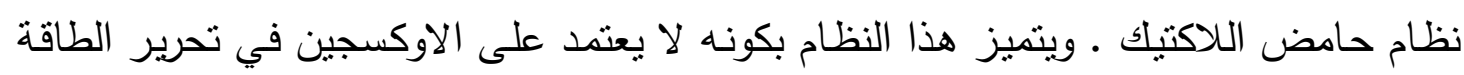

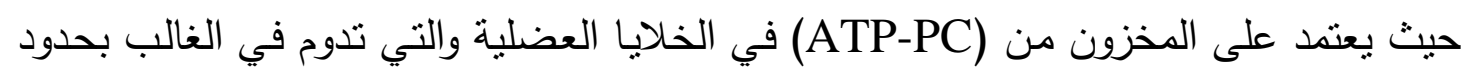

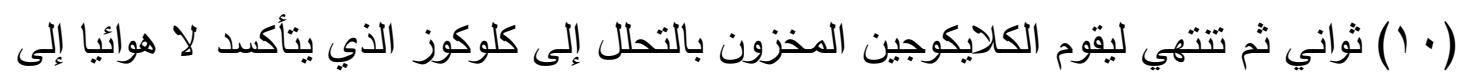

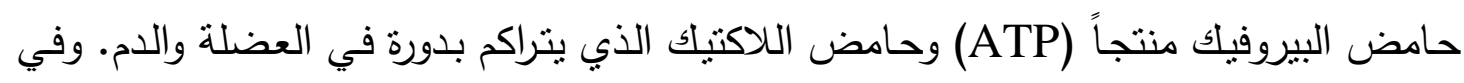

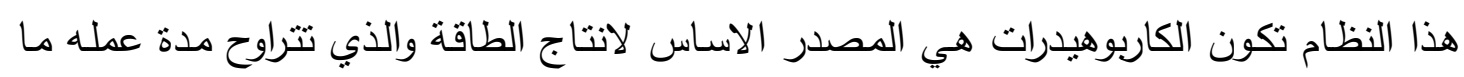

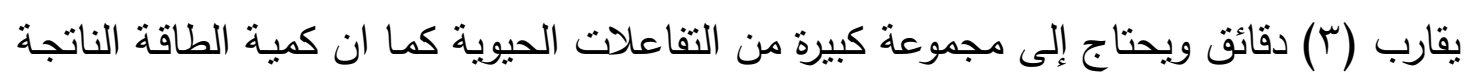

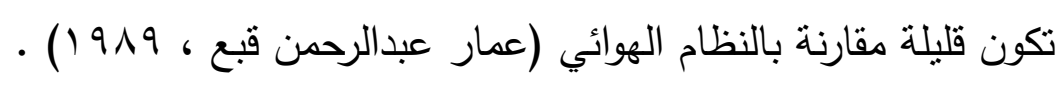

r Y Y Y r الاستفادة التطبيقية من أنظمة الطاقة :

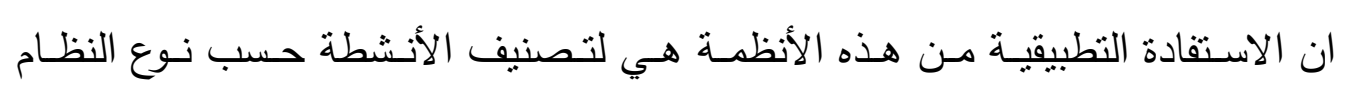
المستخدم وتركيز برامج الاعداد الرياضي حسب نوع التخصص هـ ، كما ان فهم النظام العامل في لإنظي

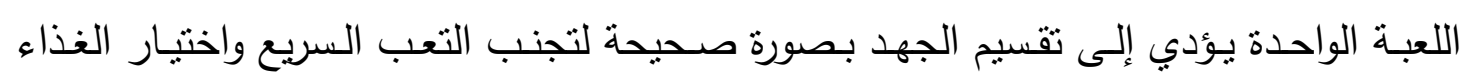

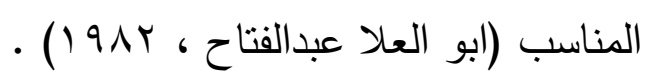

:

تقسم المطاولة إلى قسمين هما :

أ. مطاولة الجهاز الدوري التنفسي (المطاولة الهوائية) :

وتعرف بأنها قدرة القلب والجهاز الدوري التتفسي على تزويد أنسجة الجسم العاملـة بالاوكسجين والغذاء وازالة فضلات الاحتراق .

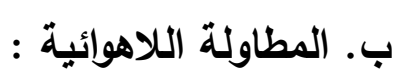
وهي لا تعتمد على الاوكسجين وتمتاز بالتقلصات العضلية السريعة والتي لا تدوم عادة

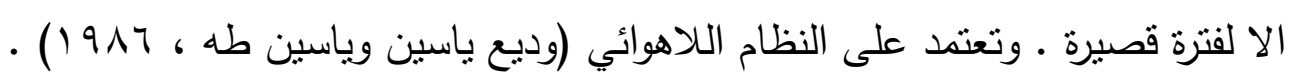

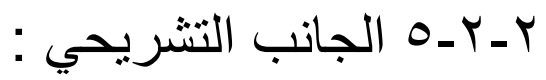
وفي هذا المجال يجب علينا معرفة بعض المصطلحات الني سيتم ذكرها في هذا البحث

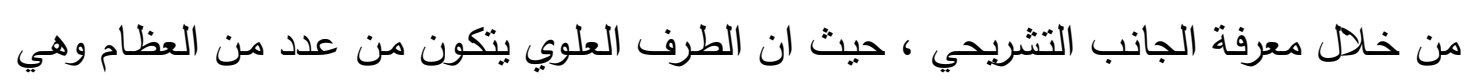

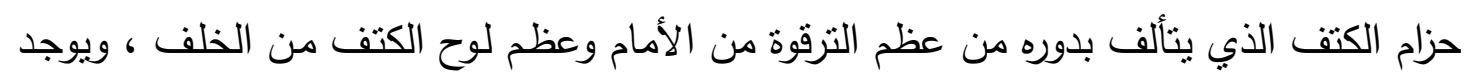


في الناحية الوحشية لعظم لوح الكتف بروز عظمي يسمى بـالنتوء الاخرمي والذي يمثل في

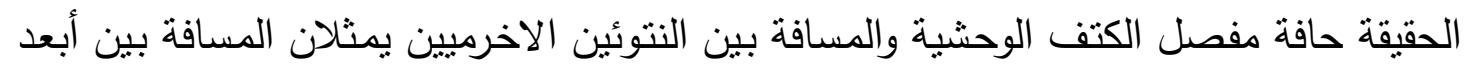
نقطتين من نقاط الهيكل العظمي للصدر ومن العظام الأخرى للطرف العلوي هو عظم العضد العند

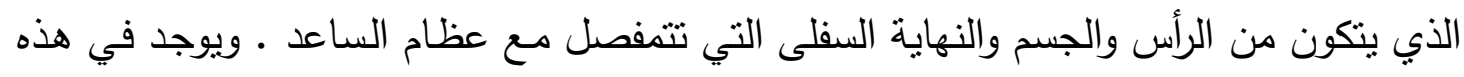

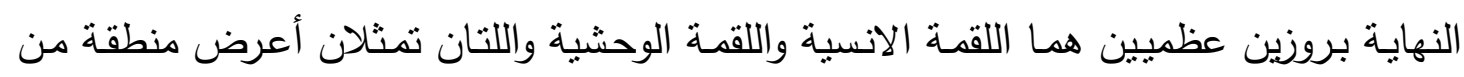

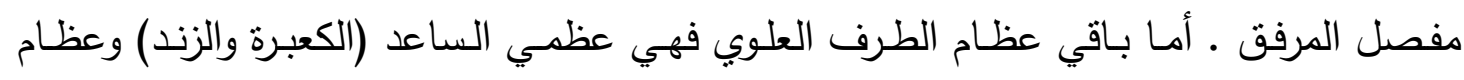

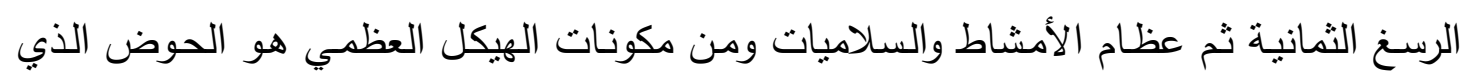

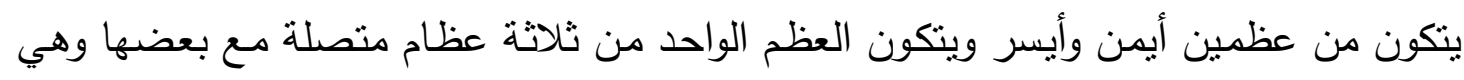

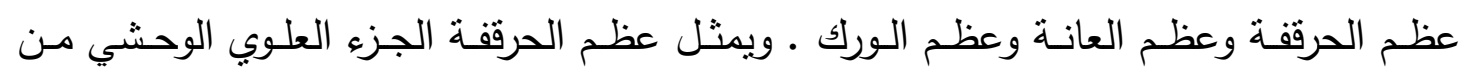
الحوض وتكون نهايته العليا على شكل قوس يسمى بالحرف الحرقفي وتمثل المسافة بين حافتي

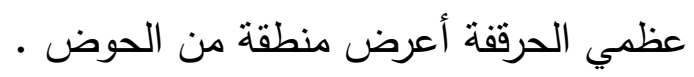

(Russell . T . et al .)

أما الطرف السفلي فيتكون من عظم الفخذ وعظم الظنبوب وعظام رسخ الكاحل والأمشاط

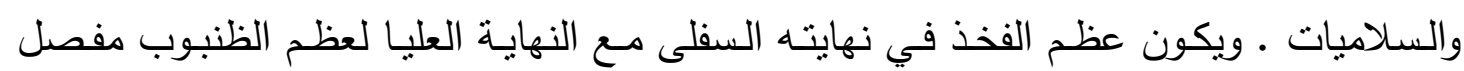
الركبة وهو مفصل زليلي لقمي ومعنى ذلك انه يتكون من اربع لقم وهي اللقمة الانسية والوحشية لعظم الفخذ واللقمة الانسية والوحشية لعظم الظنبوب ، وهذه اللقم هي بروزات عظمية كبيرة تمثل فئل

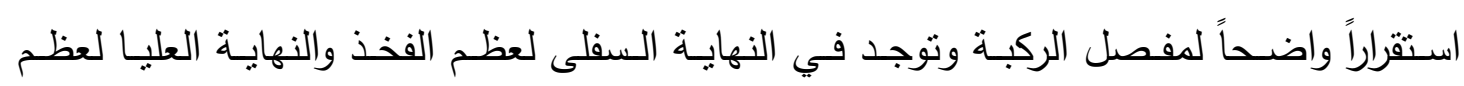
الظنبوب على التوالي ، وتكون المسافة بين لقمتي عظم الفخذ أعرض من المسافة بين لقتي

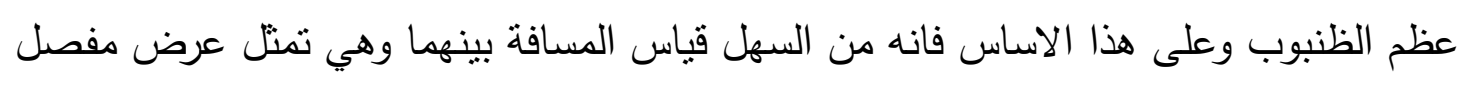
الركبة (Russel, 1983) (

$$
\text { r- اـ اجر اءات البحث: : منهج البحث : استخدم الباحث المنهج الوصفي باسلوب المسح · }
$$

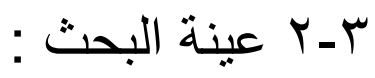

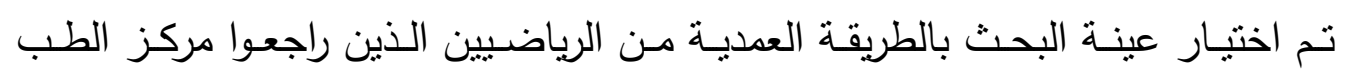

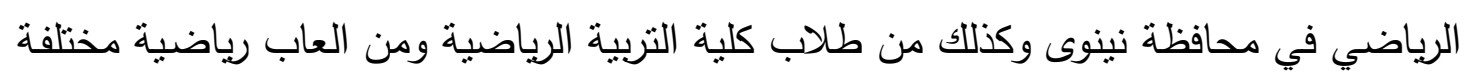

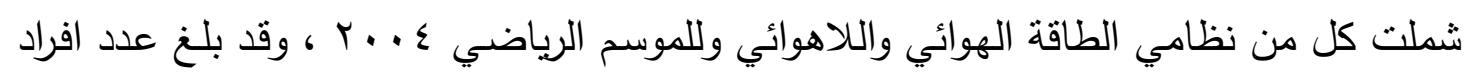

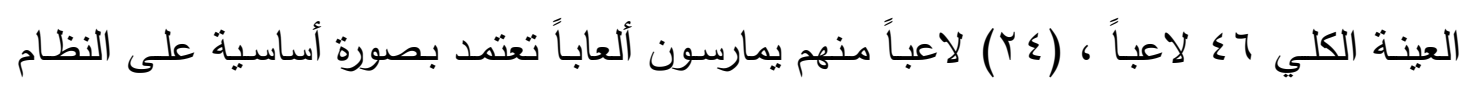


اللاهوائي و (r (Y) لاعباً يمارسون ألعاباً تعتمد بصورة أساسية على النظام الهوائي وكما مبين في

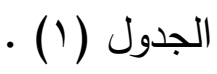

(1) الجدول (1)

مبين عدد اللاعبين وكيفية توزيعهم على الالعاب الهوائية وإللاهوائية

\begin{tabular}{|c|c|c|c|}
\hline \multicolumn{2}{|c|}{ الالعاب الهوائية } & \multicolumn{2}{|c|}{ الالعاب الللاهوائية } \\
\hline نوع اللعبة & 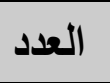 & نوع اللعبة & العدد \\
\hline سباحة طويلة & 11 & جمناستاك & $r$ \\
\hline اركاض طويلة & 9 & رفع أثقال & r \\
\hline \multirow[t]{7}{*}{ دراجات هوائية } & r & مصارعة & r \\
\hline & & بناء أجسام & $r$ \\
\hline & & تايكواندو & $r$ \\
\hline & & كاراتيه & $r$ \\
\hline & & كرة قدم & r \\
\hline & & كرة سلة & $r$ \\
\hline & $r r$ & & $r \leq$ \\
\hline
\end{tabular}

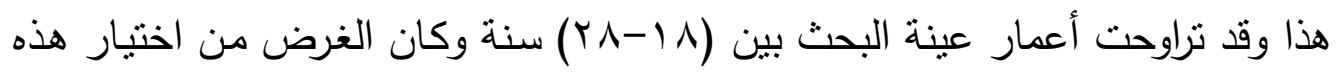

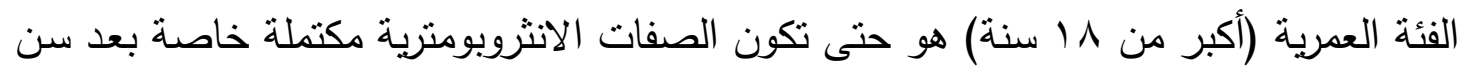

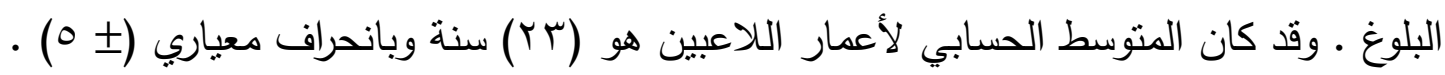

$$
\text { r-r القياسات المستخدمة في البحث : }
$$

تم أخذ القياسات التالية من كل لاعب ، وهي البحة : (الوزن بالكغم ، الطول بالسنتمتر) .

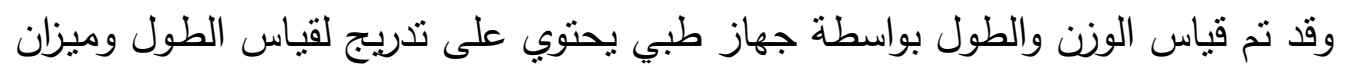

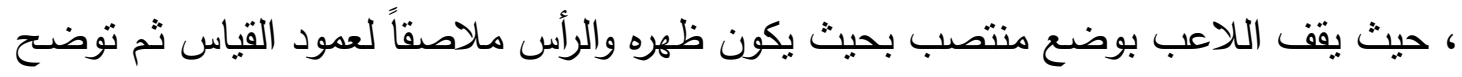

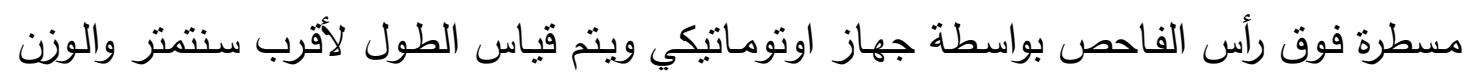

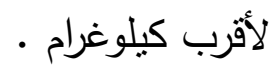

- قياس المسافة بين النتوئين الاخرمين .

- قياس المسافة بين لقمتي عظم العضد . - قياس المسافة بين عظمي الحرقفة . 
- قياس المسافة بين لقمتي عظم الفخذ .

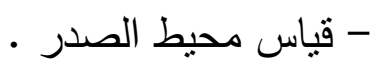

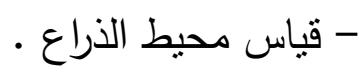

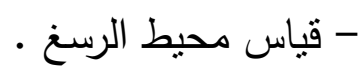

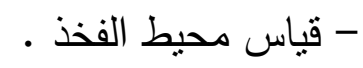

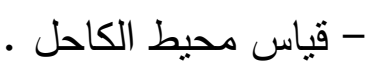

وقد استخدم الباحث جهاز الفرجال لقياس الابعاد وشريط قياس مدرج لقياس الدحيطات

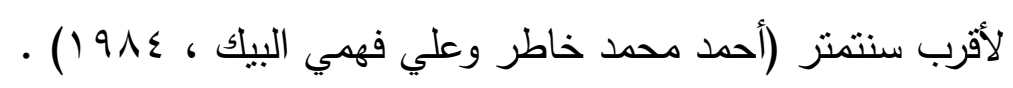

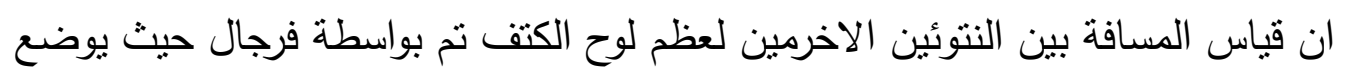

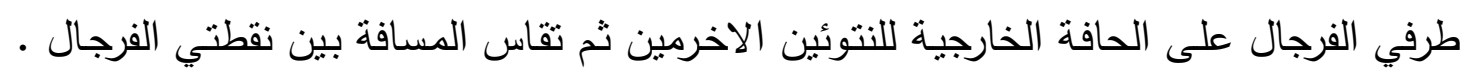
وهذا القياس يمثل في الحقيقة عرض الكتقين للاعب .

وقد تم قياس المسافة بين عظمي الحرقفة من المنطقة الوحشية القصوى للحافة الحرقفية

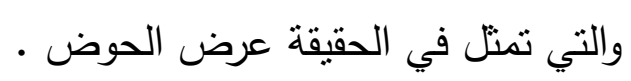

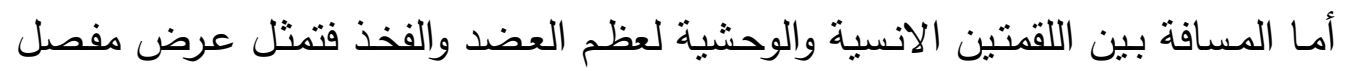

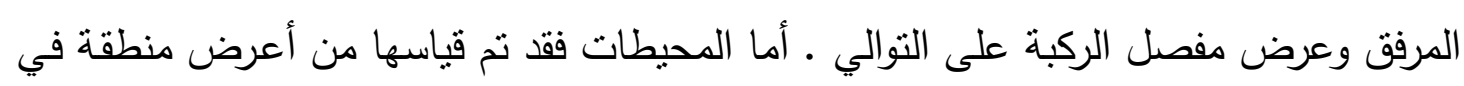

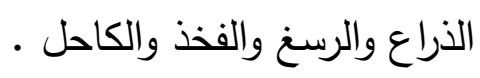

وقد تم قياس محبط الصدر بوقوف الشخص وكلتا يديه على الحافة الحرقفية لعظم الحوض ثم يتم القياس في نهاية عملية الزفير بحيث يمر الثريط اسفل الزاوية السفلى لعظم لوح

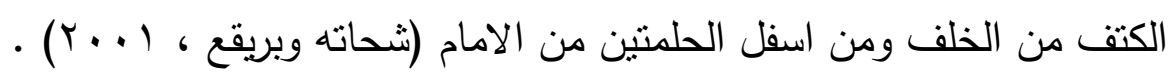

ب- الوسائل الاحصائية : -

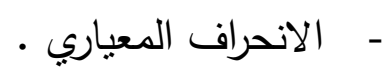

- - اختبار (ت) للعينات المنساوية ـ (التكريتي والعبيدي ، 997 ( ) 


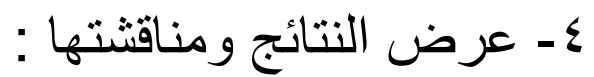

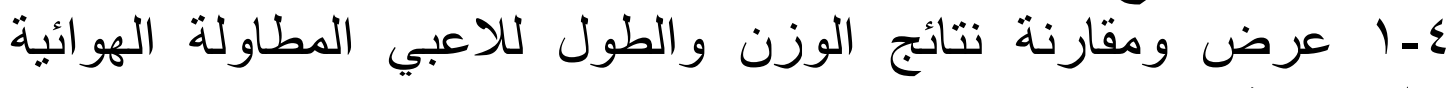
و اللاهو ائية

من الجدول (Y) يتبين ان هناك فروقاً معنوية في الوزن بين لاعبي المطاولة الهوائية

والمطاولة اللاهوائية حيث ظهرت ان قيمة (ت) المحسوبة أكبر من قيمتها الجدولية ـ ويعزو الباحث السبب في ذلك إلى حجم الكتلة العضلية التي يجب ان تتوفر في لاعبي المطاولة اللاهوائية والتي تعتمد في الاسـاس على المخزون من الـ (ATP-PC) . في حين لا يحتاج لاعبي المطاولـة الهوائية إلى كتلة عضلية كبيرة لاعتمـادهم على النظام الهوائي والمتمثل في الجهاز الدوري التتفسي الجيد ـ ويتبين من الجدول (ץ) ايضاً ان هناك فروقاً معنوية في الطول بين لاعبي المطاولة الهوائية والمطاولة اللاهوائية حيث ظهرت قيمة (ت) المحسوبة أكبر من قيمتها الجدولية ـ إذ كان طول لاعبي المطاولة الهوائية بمتوسط قدره ( V V سم في حين كان متوسط أطوال لاعبي المطاولـة اللاهوائية (77 (17) سم • ويعزى السبب في ذلك إلى ان هذه القياسات هي ضمن الصفات الخاصة المتوسطة والطويلة ان يكون الطول يتراوح بين ( V.

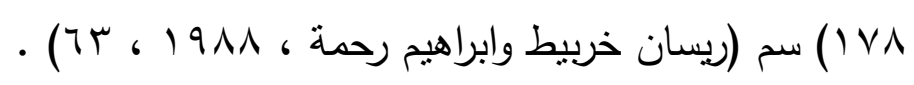

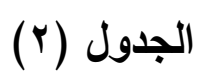

يبين الأوساط الحسابية والانحرافات المعيارية لمتغيري الوزن والطول وقيمة (ت) المحسوية

\begin{tabular}{|c|c|c|c|c|c|}
\hline \multirow{2}{*}{ قيمة (ت) } & \multicolumn{2}{|c|}{ المجموعة اللاهوائية } & \multicolumn{2}{|c|}{ المجموعة الهوائية } & \multirow{2}{*}{ المتغير } \\
\hline & $\varepsilon \pm$ & سَ س س & $\varepsilon \pm$ & سَ & \\
\hline$* r$, or & $\varepsilon, \wedge$ & $79, \varepsilon$ & $0, r$ & $70, r$ & الوزن بالكغ \\
\hline$* Y, \wedge \uparrow$ & $0, V$ & 177 & $v, r$ & iv. & الطول بالسم \\
\hline
\end{tabular}

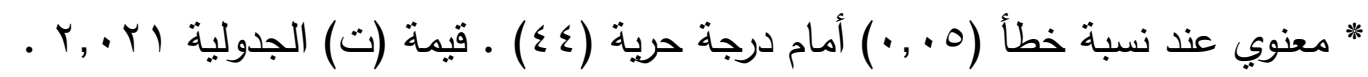




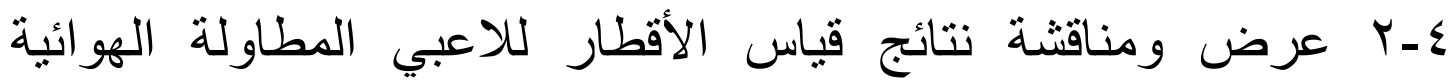
و واللاهو ائية

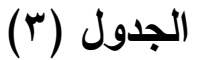
و والجدول (ب) يوضح ذلائك .

يبين الأوساط الحسابية والانحرافات المعيارية وقيمة (ت) المحسوية لقياسات المسافات لبعض تراكيب الجسم للاعبي المطاولة الهوائية والللاهوائية مقدرة بالسنتميتر

\begin{tabular}{|c|c|c|c|c|c|}
\hline \multirow{2}{*}{ قالمحسوية (ت) } & \multicolumn{2}{|c|}{ المجموعة اللاهوائية } & \multicolumn{2}{|c|}{ المجموعة الهوائية } & \multirow{2}{*}{ المتغير } \\
\hline & $\varepsilon \pm$ & س & $\varepsilon \pm$ & س & \\
\hline $1, r$ & $r, q$ & $\varepsilon r, V$ & $r, 0$ & $\varepsilon 1, \Lambda$ & المسافة بين الاخرمين \\
\hline 1,17 & $\cdot, 0$ & $\uparrow, \wedge$ & $\cdot, r$ & 7,0 & المسافة بين لقمتي العضد \\
\hline$* 0,00$ & 1,0 & rT, $\varepsilon$ & $1, r$ & $r \cdot, \Lambda$ & المسافة بين عظمي الحرقفة \\
\hline$\cdot, \mathrm{V}$ & $1, r$ & $q, r$ & $1, \varepsilon$ & 9,1 & المسافة بين لقتني الفذذذ \\
\hline
\end{tabular}

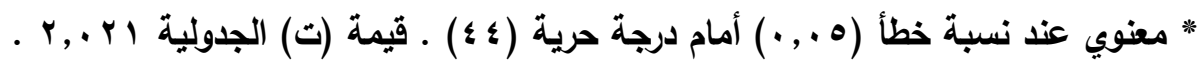

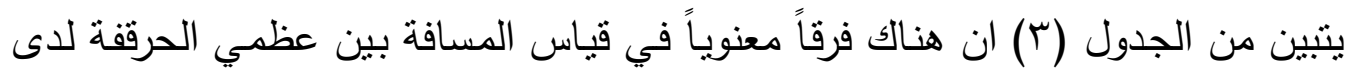

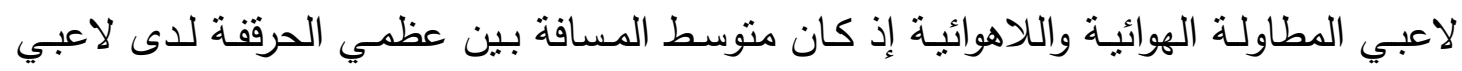

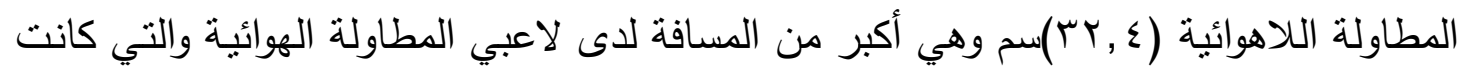

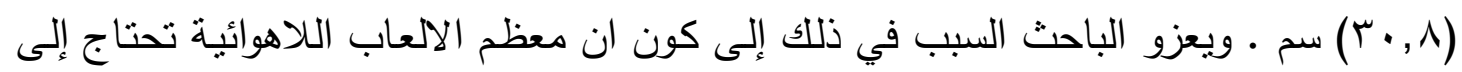

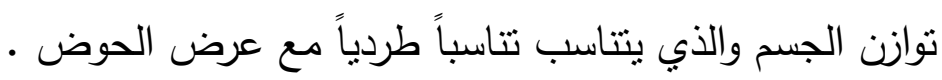

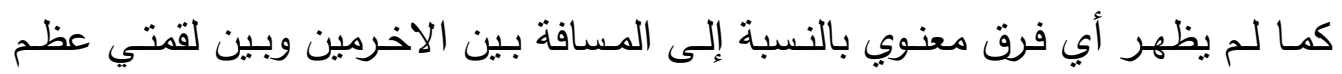
العضد ولقمتي عظم الفخذ وقد يكون السبب هنا إلى ان هذه المسافات تشكل أهمية لكلا الفريقين • الهوائي واللاهوائي

ع ـ" عرض ومناقشة نتائج قياس المحيطات لبعض تر اكيب الجسم للاعبي

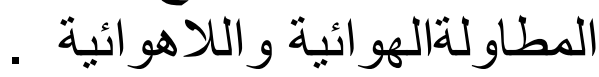

يتبين من الجدول (§) ان هناك فروقاً معنوية في محيطات الصدر والذراع والفخذ ، ولم

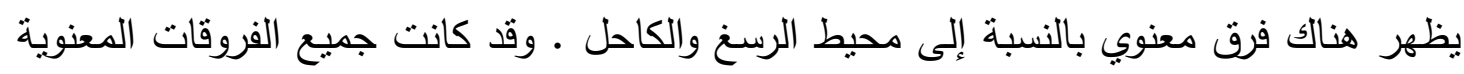
لصالح مجموعة المطاولة اللاهوائية ، ويعزو الباحث السبب ميط إلى كبر وضلى وضخامة الكتلة العضلية في أجسام لاعبي المطاولة اللاهوائية والمتنثلة في عضلات الصدية الصدر والذراعين والفخذين ـ أما بالنسبة إلى محيط الرسغ والكاحل فيرى الباحث بان التنريب الهوائي 


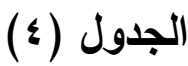

يبين الأوساط الحسابية والانحرافات المعيارية وقيمة (ت) المحسوية

لمحيطات لاعبي المطاولة الهوائية والللاهوائية مقدرة بالسنتمتر

\begin{tabular}{|c|c|c|c|c|c|}
\hline \multirow{2}{*}{ قالمحسوية (ت) } & \multicolumn{2}{|c|}{ المجموعة الللاهوائية } & \multicolumn{2}{|c|}{ المجموعة الهوائية } & \multirow{2}{*}{ المتغير } \\
\hline & $\varepsilon \pm$ & سَ س س & $\varepsilon \pm$ & سَ سَ & \\
\hline$* 4,1 Y$ & $r, 0$ & $9 \leqslant, 7$ & $\Gamma, \varepsilon$ & $9 \cdot, 1$ & محيط الصدر \\
\hline$* 0,9 r$ & $r, T$ & $r T, \varepsilon$ & $r, 0$ & $r \cdot, r$ & محيط الذراع \\
\hline $1, \vee \wedge$ & $\cdot, 9$ & 19,1 & $1, \mathrm{~V}$ & 11,7 & محيط الرسغ \\
\hline$* 0,17$ & $r, q$ & or, 1 & $r, \Lambda$ & $\sum 9,0$ & محيط الفخذ \\
\hline 1,91 & $r, r$ & $r, r$ & $r, 1$ & $r r, 1$ & محيط الكاحل \\
\hline
\end{tabular}

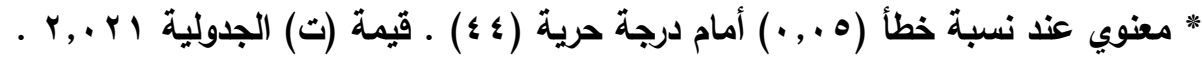

واللاهوائي لا يؤثر على هذه المحيطات كونها تتكون من عظام واربطة وأوتار العضلات

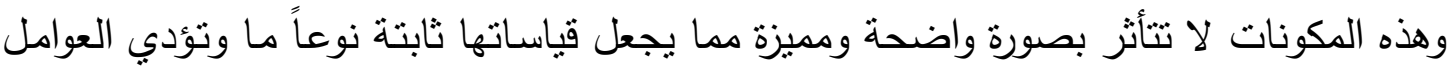
الوراثية دورا في مقدار هذه المحيطات وعلى هذا الاساس لم تظهر فروقات معنوية فيها ـ في

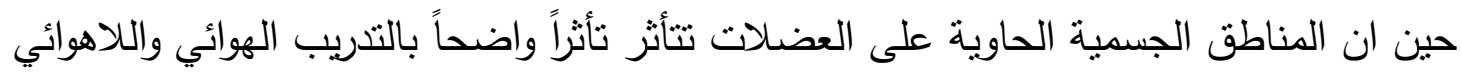

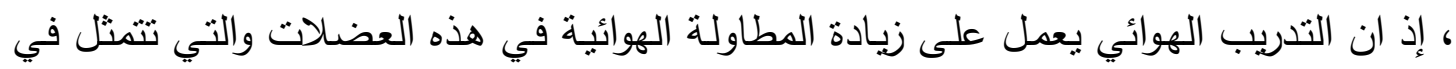
زيادة كمية الدم الواردة اليها وسرعة ازالة الفضلات إذ انها تعتمد على انتاج الطاقة بالطريقة

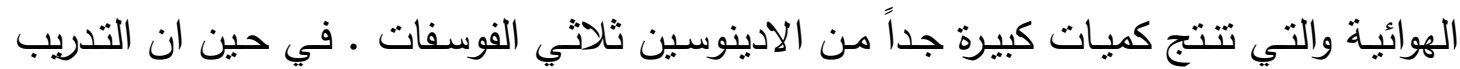

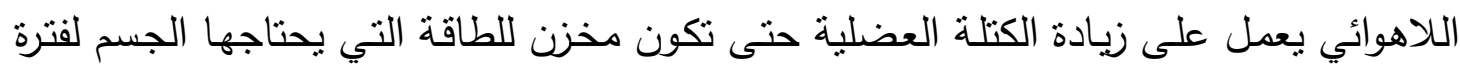

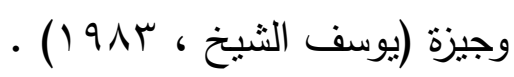

وهذا هو الاساس في التدريب اللاهوائي والمتمثل في زيادة الكتلة العضلية مما يعطي العضلات ضخامة ومن ثم زيادة في محيطات المناطق العضلية ـ 


$$
\begin{aligned}
& \text { 0ـ الاستتناجات و التوصيات : } \\
& \text { 0ـ الاستتناجات : }
\end{aligned}
$$

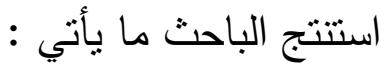

1. هنـاك فروقاً معنويـة في بعض القياسـات الانثروبومتريـة بـين لاعبـي المطاولــة الهوائيـة

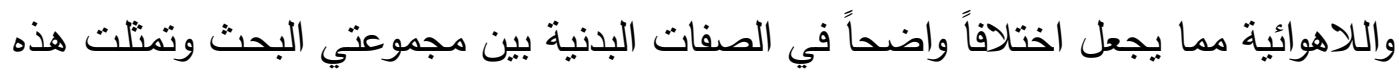

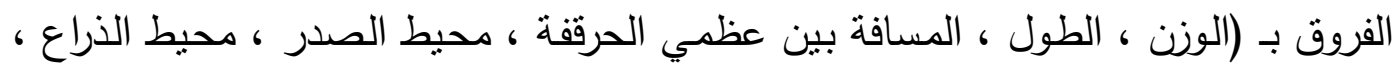

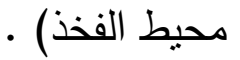
r. لم تظهر فروقاً معنويـة في بعض القياسـات الانثروبومتريـة بين لاعبي المطاولـة الهوائيـة واللاهوائية والتي تمنلت في (المسافة بين الاخرمين ، المسافة بين لقتني العضد ، المسافة بين لقمتي الفخذ ، محيط الرسغ ومحيط الكاحل) . : Y.o يوصي الباحث بدراسـة المواصفات الجسمية للاعبين عند اختيارهم لممارسـة الالعاب الرياضية التي تتناسب ومواصفاتهم الجسية بما يتلاءم مع النظام الذي تعمل به تلاكل اللعبة .

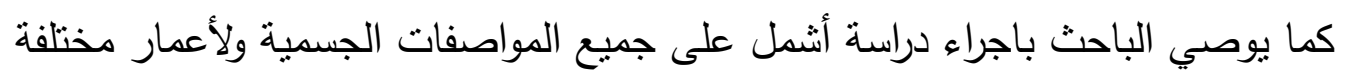

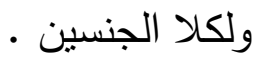




\section{المصادر العربية والأجنبية : المبية}

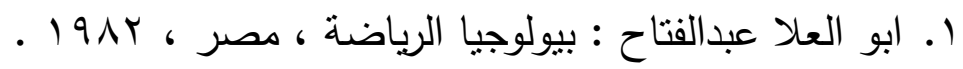

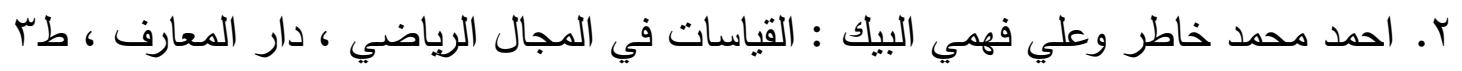
$.191 \leq 6$

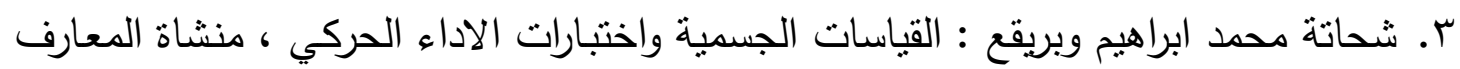

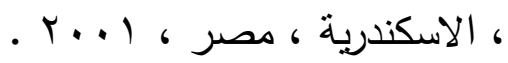

ع. ريسان خريبط : طرق اختيار الرياضيين ، دار الكتب للطباعة والنشر ، جامعة الموصل، .1911

○. عمار عبدالرحمن قبع : الطب الرياضي ، دار الكتب للطباعة والنشر ، جامعة الموصل ، .1919

7. وديـع باسين التكريتي وحسن محمد عبد العبيدي : التطبيقات الاحصائية لبحوث التربيـة الرياضية ، دار الكتب للطباعة والنشر ، 1997 ـ جامعة الموصل

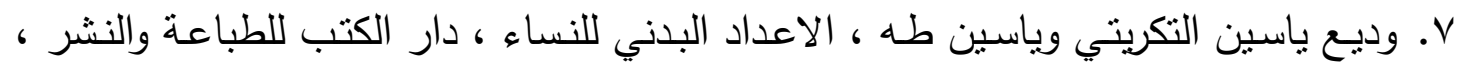

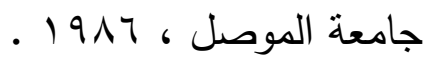

1. يوسف الثيخ : فيسيولوجيا الرياضـة والتدريب ، الاسكندرية ، مطبعة بناء الفكر ، مصر، $.191 \mathrm{r}$

9. Astrand, L. Text book of work physiology, 1979.

10.Behnke, A.R. et. al. Shape and composition of several types of athlets. I. Sport Med. 1996. (31-32)

11.Bell-W. Distribution of skin folds and differences in body properties is young adults. I. Of sport Med. 1995. (85-86)

12.Cureton. T.K. Physical fitness of champion athlets. British . J. of sport medecine 1995.

13.Klissoures, V. Prediction of potential difference with special reference to Veniality. I. Sport Med. 1993. (44-45)

14.Micheal, L. Muscle and Fitness. 1982. (122-123)

15.Russel, T. Wood burn essential of human anatomy. Oxford. 1983.

16.Thomas Reilly, Sport fitnees and sport injuries. 1981. Edinburg Press 